\title{
"Acordem! Nossos Relógios Estão Lentos em Relação ao Nosso Tempo
}

Ken Booth**

Boa tarde a todos. É uma grande honra para mim ser convidado para assistir à vossa comemoração. Gostaria de congratular o Instituto por esse notável aniversário. Devo continuar o discurso em inglês. Desculpem-me. ${ }^{1}$

Sinto-me bastante embaraçado por ser a única pessoa nesta sala que não fala português, especialmente porque serei a única pessoa a segurar o microfone nos próximos 45 minutos. Mesmo assim, o emba-

\footnotetext{
* Este é o texto do discurso feito em 22 de novembro de 2007 na celebração do vigésimo aniversário da inauguração do curso de pós-graduação do Instituto de Relações Internacionais da Pontifícia Universidade Católica do Rio de Janeiro (IRI/PUC-Rio). Por ser o texto de um discurso, não são feitas referências. No entanto, os argumentos em sentido amplo estão explorados em BOOTH, Ken. Theory of world politics. Cambridge: Cambridge University Press, 2007. Discurso traduzido por Marisa Gandelman. ** E. H. Carr Professor, Aberystwyth University, Wales, Reino Unido. E-mail: kob@aber.ac.uk.
}

CONTEXTO INTERNACIONAL Rio de Janeiro, vol. 30, ํㅡㄹ, maio/agosto 2008, p. 249-266. 
raçoé suportável, porque é uma honra tão especial ter sido convidado para a sua celebração e especialmente por ter a oportunidade de falar a vocês sobre o estado do mundo e o estado da disciplina. Muito obrigado.

Gostaria de agradecer a uma série de pessoas por terem me convidado e por tomarem conta de mim tão bem. Quero agradecer particularmente à diretora, professora Mônica Herz, e ao professor Nizar Messari. Pela ajuda em me fazer chegar aqui em circunstâncias de várias tentativas, quero agradecer os esforços especiais de Natacha Oliveira.

Passei a vida toda, desde os 18 anos, estudando este tema fascinante das Relações Internacionais (RI) - e ainda me vejo muito como um estudante. Algumas coisas são diferentes, é claro, de quando eu comecei. Meu escritório é bem melhor e sou muito mais bem pago, mas, provavelmente, me divirto menos. Acho que sei muito mais, mas sei também que tenho menos certeza sobre tudo. (Todos nós sabemos que a realidade contra a qual nos chocamos fora desta sala é uma poderosa professora. E, a este respeito, eu gosto sempre de citar as palavras de nobre inglês do século XVII que disse pesarosamente: "Antes de me casar, eu tinha seis teorias sobre como educar crianças; agora, tenho seis crianças e nenhuma teoria").

Quando me graduei, assim como todos os outros estudantes meus amigos, eu vinha de uma família na qual ninguém jamais havia estado na universidade. Muitas coisas eram estranhas para os nossos familiares. Uma das minhas histórias favoritas a respeito desses ritos de passagem é de um estudante que chega à casa e conta à sua família que se graduou com notas altas e planeja fazer um $\mathrm{PhD}$ :

- “Um PhD?", um de seus tios fala, de forma meio crítica (pensando que ela já tinha gastado muito tempo com educação). - "O que é um $\mathrm{PhD?"}$ 
“Acordem! Nossos Relógios Estão Lentos em Relação ao Nosso Tempo"

- "É pesquisa", o estudante diz. "Serei doutor em filosofia".

O tio recobra-se do que ouviu: " “Doutor!”, ele diz com tom de aprovação (pensando na perspectiva de um bom salário). "Doutor em filosofia", completa, com um pouco menos de certeza, acrescentando: - "E exatamente qual tipo de doença é filosofia?"

Para mim, aprofundar-me mais no tema como um graduado e mais além, com mais filosofia, mostrou-se ser mais uma cura do que uma doença. Ajudou a pensar mais claramente sobre aquilo que eu sabia. E isso me ajudou a descobrir que muito do que me ensinaram estava errado. $\mathrm{Ou}$, pelo menos, isso foi o que passei a pensar.

Mas se as coisas mudaram na minha trajetória particular de estudante, uma coisa permaneceu igual. Trata-se da excitação de acordar cada dia com a expectativa de aprender alguma coisa nova a respeito do mundo. Este é um fantástico privilégio.

Trabalhar com graduados sempre foi um prazer profissional particular para mim - e eu também comemoro um aniversário este ano. Há exatos quarenta anos atrás - em 1967 - eu comecei a dar aulas na pós-graduação e a supervisionar teses. Boa parte do meu tempo desde o começo dos anos 1990 gastei na construção de um programa de PhD no meu próprio departamento. Agora temos uma larga e vibrante comunidade $\mathrm{PhD}$ e, assim como o resto dos meus colegas, sinto que o trabalho feito por nós de criação das condições para a próxima geração de professores e pesquisadores é uma das partes mais gratificantes da nossa atividade. A reputação do departamento alastrou-se inclusive na América do Sul. Estou realmente muito satisfeito de dizer que agora temos a nossa primeira candidata a $\mathrm{PhD}$ do Brasil Laura Lima - e ela, por uma maravilhosa coincidência, está aqui na platéia hoje e tem sido um guia perfeito para me apresentar o Rio. Meus agradecimentos também à Laura. 
Por isso, eu me identifico muito com as esperanças e a energia que levaram àquilo que o Instituto celebra hoje e estou muito honrado de fazer parte desta comemoração.

O título da minha apresentação, com uma distorção, tem origem em algumas palavras do grande dissidente soviético Alexander Solzhenitsyn.

"Acordem", ele disse aos homens de Moscou que governavam a decadência do Estado soviético e seu império na Europa oriental: "Seus relógios estão lentos em relação aos nosso tempos".

A alegação de Solzhenitsyn contra os relógios lentos daqueles cuja verdade era (localmente) hegemônica é o meu ponto de partida para o tópico sobre o qual me pediram para falar a respeito: o estado da disciplina das Relações Internacionais.

Eu quero olhar o estado da disciplina em relação ao estado do mundo (comparando os relógios nas nossas salas de aula, se vocês quiserem, com o ritmo da política mundial lá fora). A este respeito, eu mudo o sentido das palavras de Solzhenitsyn. Penso que nós devemos "acordar", porque os relógios de nossa disciplina estão lentos em relação ao tempo do mundo - da mesma forma que penso que os relógios dos agentes da política mundial que são nosso objeto de estudo (governos e nações) também estão lentos.

Acredito que um olhar panorâmico é especialmente apropriado para uma comemoração de aniversário porque aniversários nos fazem pensar sobre as origens - neste caso, as origens de nossa disciplina e a questão básica: para que (ou quem) servem as Relações Internacionais acadêmicas?

Sei praticamente de cor uma resposta importante para essa pergunta, porque as origens do campo de estudo se fundam na minha universidade - onde o primeiro departamento de política internacional do 


\section{“Acordem! Nossos Relógios Estão Lentos em}

Relação ao Nosso Tempo"

mundo foi criado. David Davies, membro do Parlamento e oficial na Primeira Grande Guerra 1914-1918, estabeleceu o departamento em Aberystwyth e de certa forma inventou as Relações Internacionais acadêmicas como um memorial para os estudantes que haviam lutado e morrido na Grande Guerra. Com uma fé liberal na educação, ele esperava espalhar o internacionalismo e construir um mundo pacífico. A disciplina, dessa forma, começou com uma relação particular com a realidade - não somente de interpretar o mundo, mas de mudá-lo. Para mim, este ainda é o caso, e o desafio para os estudantes de hoje não é de forma alguma menor do que quando David Davies começou. O desafio de hoje, conforme eu o vejo, é buscar resposta para as questões jogadas pelo que mais adiante eu chamo de $o$ grande ajuste de contas e se apresenta para a humanidade globalmente, no mínimo no próximo meio século.

Minhas palavras sobre isso tudo são dirigidas particularmente àqueles entre vocês que estão hoje nos seus 20 anos. O título começa com as palavras "Acordem!" Se eu fizer o meu trabalho razoavelmente, minha chamada manterá vocês acordados durante a próxima meia hora, mas se eu fizer muito bem espero mantê-los acordados a noite inteira.

Durante esta fala, eu gostaria que perguntassem a si mesmos que mundo vocês desejam descrever nos meados do século, quando estiverem chegando ao fim de suas carreiras. Quando vocês tiverem vislumbrado este mundo, uma vez que um novo mundo não se constrói da noite para o dia, pensem sobre o que precisaria ser feito em 2040 para se ter alguma esperança de chegar aonde querem que o mundo esteja em meados do século (digamos em torno de 2047, quando o Instituto celebrar seu $60^{\circ}$ aniversário) e assim o que precisa ser feito lá por 2030 e 2020, e assim por diante, cada vez mais próximo do presente -e, dessa forma, o que precisa ser feito amanhã para tornar possível o mundo que vocês gostariam de habitar quando seus netos estiverem crescendo. 
Uma coisa eu posso lhes garantir com certeza: as relações internacionais nos meados do século não serão como hoje.

A sociedade humana encara globalmente uma crise mundial histórica na primeira metade deste século. Eu chamo de o grande ajuste de contas. Trata-se de um grande ajuste de contas porque confronta a sociedade humana em termos globais com o mais fundamental dos problemas de vida em conjunto neste planeta cada vez menor. Um "ajuste de contas" se dá quando ficamos frente a frente (como indivíduos ou sociedades) com os custos acumulados e futuros gerados pelo nosso comportamento.

Quando olho para meados do século, vejo uma história futura de riscos convergentes e é em relação ao fracasso geral da maior parte da nossa disciplina de dar conta da dinâmica determinante de nosso tempo que faço a alegação de que nossos relógios estão lentos.

A não ser que haja mudanças radicais na maneira como nos relacionamos uns com os outros, as décadas que estão por vir ameaçam ser um período de considerável tumulto. Duas tendências provocam esta instabilidade. Primeiro, as pressões resultantes das mudanças das condições materiais. Segundo, as tensões que crescerão porque as idéias que ao longo dos séculos vêm construindo as atuais política e economia mundiais não funcionam.

O futuro mais desanimador pode ser amplamente eliminado do pensamento se boas decisões forem tomadas com bastante rapidez em todos os níveis, mas há poucos sinais no presente de que isso aconteça como resultado das decisões dos Estados, líderes e sociedades mais poderosas - e o nosso campo não está ajudando.

A razão para prever uma era de crise pode ser rapidamente sumarizada. Eu começo com a dinâmica material. 


\section{“Acordem! Nossos Relógios Estão Lentos em}

Relação ao Nosso Tempo"

Primeiro: o perigo do "caos climático" e tudo o que isso significa para a agricultura, alimentos, migração descontrolada, instabilidade econômica e colapso social.

Segundo: a contínua destruição da natureza. Isso inclui a redução da biodiversidade, erosão do solo, o corte de florestas tropicais e o desaparecimento de todas as fontes tradicionais de proteína, tais como os estoques de peixe.

Terceiro: a depreciação de suprimentos "essenciais" de energia óleo e gás em particular. Na falta de transformações tecnológicas surpreendentes, podemos esperar um conflito crescente em torno das fontes de energia não renováveis.

Quarto: a crescente nuclearização da política internacional. Mohamed ElBaredei, o diretor da Agência Internacional de Energia Atômica (AIEA), acredita que cerca de 36 Estados têm potencial capacidade atômica. Somando-se aos Nuclear Weapon States (NWS) existentes, serão quarenta a cinquienta países em torno de 2050, ou antes. Como será a "política entre as nações" com tantos dedos sobre botões nucleares - para não falar no aumento que uma ampliação dessas pode gerar nas perspectivas de terroristas conseguirem acesso a materiais nucleares?

A mudança material final diz respeito à população global.

Quando eu nasci, existiam cerca de 2 bilhões de pessoas na Terra. Quando eu morrer, seremos 8 bilhões (menos um). Isso significa a adição de 6 bilhões de consumidores da natureza durante apenas o tempo da minha vida. Em meados do século, a população global pode alcançar cerca de 9 a 11 bilhões (o que significa ultrapassar o dobro de pessoas de hoje). Como elas serão alimentadas? (Um relatório recente da Organização das Nações Unidas (ONU) declarou que necessitamos dobrar a produção de alimentos do mundo para alcançar o objetivo do milênio de diminuição pela metade do número 
de famintos no mundo.) O que falar sobre moradia decente? (Antes de 2030, estima-se que um terço de nós viverá em favelas). E a respeito da água? (O relatório da ONU afirma que, se a tendência atual permanecer, perto de 2 bilhões de pessoas viverão em áreas de absoluta escassez por volta de 2025.) O que vão fazer os vastos exércitos de jovens desempregados nas futuras megacidades? De onde virão os empregos? Como serão contidas as pressões sociais? Em tais circunstâncias quem poderá acreditar que a tolerância transcenderá o preconceito racial, a democracia derrotará a ditadura, e a paz prevalecerá sobre a política de "sangue e posses"?

Ao lado dessas mudanças materiais, existe ainda o perigo de outras divisões relacionadas à cultura, ideologia e religião - todas elas vão minar as perspectivas de respostas coletivas aos problemas globais comuns.

O fim da Guerra Fria supostamente representou o fim da história - o desfecho das grandes questões políticas, econômicas e sociais do passado. Ao invés disso, a história não terminou e desde os anos 1990 o fanatismo/extremismo de um ou de outro tipo nos ronda.

Vimos um hipernacionalismo nos Bálcãs; mentalidade genocida em Ruanda e Darfur; extremismo islamita, cristão e hindu e assim por diante. O mundo ocidental, de sua parte, foi dominado por aquilo que J. K. Galbraith chamou de "cultura do contentamento" - altamente egoísta e auto-obsessiva com um desligamento total de inquietações (embora não com falta de lágrimas de crocodilo por parte dos líderes políticos).

Ao invés de gozar os dividendos da paz, os anos 1990 foram complacentes e desperdiçados. Uma de minhas numerosas críticas a George W. Bush é que ele foi um presidente tão desastroso que fez até mesmo a Presidência de Bill Clinton parecer boa. 
“Acordem! Nossos Relógios Estão Lentos em Relação ao Nosso Tempo"

A liderança do mundo não está em mãos seguras. Vocês podem acreditar que vivemos em um mundo em que um político como Tony Blair, que levou seu país a uma guerra insensata, desnecessária e em última instância desastrosa, ganha a função de "enviado da paz no Oriente Médio"? Vocês não poderiam imaginar!

Mas o desafio do grande ajuste de contas não pára ali, na convergência da crise material e da insensatez. Em um nível mais profundo, ainda estamos diante de um desafio. As verdadeiras idéias que nos fizeram - que fizeram a política global ser o que é hoje - estão sendo colocadas em xeque. Refiro-me àquelas idéias que um dia foram pensadas como resposta para as grandes questões da vida: as opressões do patriarcado, o proselitismo religioso, a exploração do capitalismo, o egoísmo estadista do sistema westfaliano. Todas juntas se colocam no caminho do nosso aprendizado de vida conjunta neste planeta cada vez menor, mais explorado, crescentemente populoso, multicultural, multinacional e multirreligioso.

As idéias que construíram amplamente a política mundial e a sociologia global estão fora do tempo no século XXI. Olhem em volta! A política mundial não funciona para a grande maioria da população mundial, nem para a natureza - da qual nós todos dependemos.

Sendo assim, como serão as relações internacionais em meados do século depois de várias décadas de sobrecarga convergente do sistema e contínuo estresse global? Tenho um palpite de que será um tempo pronto para o extremismo, e a política de "sangue e posses". Será um tempo de ditadores e movimentos autoritários que podem convencer pessoas desesperadas de que eles têm as respostas. (Um partido de extrema direita na Ucrânia há alguns anos atrás foi consideravelmente franco quanto às suas intenções, prometendo aos eleitores: "Votem em nós e vocês nunca mais precisarão votar outra vez".)

Vocês podem perguntar: se é assim tão óbvio que estamos com um problema global, por que o campo de estudo não melhora? De modo 
geral, respondo que os seres humanos normalmente não enxergam a realidade até muito tarde (lembrem-se que em grande parte da história as pessoas mais inteligentes do mundo estavam convencidas de que o mundo era plano). O fato é que os humanos freqüentemente não querem enxergar a realidade (freqüentemente nós pensamos que mudar de idéia é mais difícil do que extrair um dente).

Quero ressaltar que meus comentários sobre a disciplina são especificamente dirigidos para a corrente majoritária anglo-americana das Relações Internacionais - que conheço melhor. (Se alguém me puder dizer que é radicalmente diferente em algum outro lugar, eu ficaria muito interessado em conhecer.) Naquelas partes que conheço melhor, não vejo um sentido de urgência em nossos debates: publicações periódicas estão cheias de discussões internas domésticas; muito trabalho parece estar focado no trivial em oposição ao central; e tem sempre uma preocupação com a contagem de pontos das batalhas teóricas mais do que em usar a teoria para se engajar com os temas mais importantes que afetam pessoas reais em lugares reais. (Eu fiquei interessado quando cruzei com um filósofo francês há alguns anos atrás que identificou problemas semelhantes em seu próprio tema, descrevendo muito da profissionalização em sua matéria como "uma fuga do real".)

Apresento sete amplas razões para este veredicto relativamente às RI.

Primeira: o domínio do superpoder acadêmico dos Estados Unidos. (Temos sempre de começar atacando os Estados Unidos, mas faço isso, assim espero, como uma crítica amigável, porque os Estados Unidos representam uma sociedade de muito talento, sabedoria e espírito humano. Infelizmente, têm sido freqüientemente também um Estado muito poderoso, muito propenso aos governos insensatos e arrogantes, e muito sob o domínio de corporações vorazes.) 
“Acordem! Nossos Relógios Estão Lentos em Relação ao Nosso Tempo"

A disciplina nos Estados Unidos tem sido em grande parte restrita no interesse e no método. Penso as RI nos Estados Unidos como alguém com uma lâmpada em uma sala escura. Em alguns momentos, estão focados nesta parte da sala, em outros momentos naquela, mas a concentração nunca é completa e consistente. Nos últimos seis anos, a lâmpada brilha sobre o terrorismo. Um colega contou-me recentemente que uma pesquisa demonstra que a cada seis horas um novo livro sobre terrorismo é publicado. A política mundial condena, diariamente, cerca de 30 mil crianças à morte por doenças que poderiam ser evitadas, no entanto os recursos do nosso tema são seqüestrados por um episódio terrorista espetacular de assassinato em massa na terra do superpoder acadêmico. Faço esta comparação não para desonrar aquelas pessoas assassinadas em circunstâncias verdadeiramente horripilantes em 11 de setembro, mas sim para pedir que honremos aqueles que morreram sem serem vistos de $1^{\circ}$ de janeiro até 31 de dezembro.

Segunda: a disciplina está dominada por aquilo que Robert Cox chama de "teoria solução de problema". O termo diz respeito às teorias que visam fazer com que as instituições e idéias existentes funcionem melhor, mais do que repensar essas instituições e idéias. $\mathrm{O}$ realismo foi a chamada "teoria solução de problema" hegemônica em nosso campo. Este tipo de solução de problema resulta em horizontes de curto prazo. De fato, os horizontes de curto prazo e as ameaças imediatas fazem da maioria de nós realistas. Se um homem entrasse neste salão segurando uma bomba e ameaçando explodi-la, minha expectativa seria de que alguém o acertasse com uma cadeira antes que ele conseguisse fazer isso. Mas eu acredito que a melhor maneira de empregar a capacidade dos acadêmicos não é estudando formas de agarrar homens que correm para dentro de uma sala cheia com uma bomba (a abordagem solução de problema tática da corrente majoritária dos estudos de contraterrorismo), mas sim tentando entender em primeiro lugar por que o seu próximo haveria de querer fazer uma coisa dessas. 
Terceira: existe uma compartimentalização de saber dentro das RI. Nós subestimamos a dimensão extra do perigo futuro que virá da convergência de todas as tendências negativas sobre as quais falei. Quanto maior o número de tipos de estresse convergindo sobre os tomadores de decisão ao mesmo tempo, maior será a dificuldade em tomar decisões sábias quando confrontados com o grande ajuste de contas. Somos desencorajados de olhar para essas linhas de estresse convergentes porque nossos diversos subcampos trabalham em suas próprias caixas, e não conversam suficientemente uns com os outros. As pessoas de estudos estratégicos trabalham com coisas militares, os ambientalistas com a natureza, a turma da economia política internacional estuda os fluxos de riqueza enquanto outros grupos formam sectos ainda mais hermeticamente fechados. A matéria fragmentou-se, marcada por mais e mais periódicos com áreas de assunto cada vez mais estreitas, e conferências mais e mais especializadas do que nunca.

Quarta: a tentação do relativismo. Esta é a tendência que favorece o local sobre o global, a identidade política sobre a igualdade universal, as micronarrativas sobre o universalismo, e o comunitarismo sobre o cosmopolitismo. Freqüentemente, do modo do pós-estruturalismo na nossa disciplina, esses valores de preferências obstruem a promoção das respostas globais aos problemas globais. Eles deixam o poder onde ele está. E mais: isso é feito freqüentemente em uma linguagem que é tão especializada e obscura que convence muitos de que é brilhante. Penso que, como estudiosos, temos o dever de tentar falar em linguagem acessível. O que se segue não é uma piada, e de alguma forma é desrespeitoso, mas revela um pouco como muitos se sentem (e isso me foi dito por um estudante). Qual é a diferença entre um membro da máfia e um pós-estruturalista? Um mafioso lhe faz uma oferta que você não pode recusar; um pós-estruturalista lhe faz uma oferta que você não consegue entender. 
“Acordem! Nossos Relógios Estão Lentos em Relação ao Nosso Tempo"

Quinta: o caráter inato de muitos dos trabalhos publicados. Olhem os periódicos. Estão cheios de artigos sobre artigos prévios e placares acadêmicos. Existe um belo ditado árabe que diz: "Os cães ladram e a caravana passa". Este ditado se refere a fazer muito barulho e confusão temporariamente, enquanto a vida real - as coisas importantes segue em frente. Assim são muitas das conferências acadêmicas muitos de vocês devem ter ido à International Studies Association (ISA), que é a perfeita expressão disso. É muito barulho e bagunça em uma bolha - literalmente de dois a 3 mil tipos das RI isolados em um hotel cinco estrelas, falando até não poder mais sobre RI, e ao mesmo tempo desconectados das pessoas reais nos lugares reais. (Uma vez dito isso, espero ver alguns de vocês na próxima ISA em São Francisco em março de 2008.)

Sexta: dominação do tema, tradicionalmente, por valores masculinos. Acredito que tais valores ainda ajudam a definir o que estudamos - violência política mais do que opressão econômica, o trabalho de diplomatas mais do que dos médicos, segurança militar em vez de segurança humana, e poder em vez da pobreza. Não estou dizendo que o trabalho de soldados e diplomatas não seja relevante - longe disso (não estou interessado em nenhuma das versões dos chamados estudos críticos de segurança se a dimensão militar é tendenciosamente ignorada). No entanto, se vamos nos engajar com o real, precisamos olhar mais além daquelas áreas nas quais as preferências e tendências masculinas tendem a se estender. Lembrem da atriz que disse nos anos 1930 ter tido dois casamentos, primeiro com um fascista e depois com um marxista, e que nenhum dos dois maridos levava o lixo para fora. (O que ela estava dizendo de fato era que os homens ladram suas diferenças políticas enquanto a vida real, representada pelos caminhões de lixo, passa.)

Sétima: existe uma complacência dos poderosos. O realismo tem grande importância na construção das RI, na teoria e na prática. É a teoria dos poderosos, para os poderosos, de autoria dos poderosos. 
Uma ilustração dessa visão de cima para baixo é o best-seller de Thomas Friedman, o guru da globalização. O seu livro mais conhecido, The world is flat, é uma glorificação dos benefícios da globalização. Mas tipicamente perde-se muita coisa. Para dar um exemplo da América do Sul: a Colômbia ganha não mais do que uma menção de passagem no livro de Friedman, e tal menção é feita em uma lista de Estados que não dão direitos aos credores. Não sou um especialista em Colômbia, mas penso que a política e a economia daquele país devem valer um comentário por outras razões. Aqueles que defendem a idéia de "Terra achatada" no presente - como Thomas Friedman - da mesma forma que no passado não conseguem ver além dos horizontes de suas próprias crenças. Mas não devemos ficar satisfeitos com isso. Cada um de nós deve perguntar a si mesmo: quais são os limites dos nossos horizontes?

Finalmente, como a disciplina pode melhorar para se confrontar com o grande ajuste de contas? Eu ofereço um desafio de cinco "Es": etnocentrismo, igualdade (equality), economia, emancipação e todo mundo (everyone).

Etnocentrismo. Devemos experimentar e de fato lidar com as nossas próprias percepções etnocêntricas e com aquelas refletidas em um campo tão dominado pelo etnocentrismo do superpoder acadêmico e militar do mundo. Etnocentrismo significa ser preso à própria cultura, interpretando o mundo somente por meio de lentes nacionalistas de seu próprio país. Nós todos sabemos a respeito da guerra global contra o terror - a luta dos Estados Unidos contra aqueles que Bush chama de "o povo do mal" no mundo. Nós todos precisamos ver a nós mesmo como os outros nos vêem. Um amigo recentemente me mandou um cartão postal que me fez pensar sobre isso. Basicamente, a mensagem na frente dizia a Washington para olhar no espelho e tentar ver a si mesmo como os outros o vêem. Mostrava três índios nativos norte-americanos - pareciam consideravelmente ameaçadores e carregando armas, tudo isso sobre um cenário de oeste selva- 
“Acordem! Nossos Relógios Estão Lentos em Relação ao Nosso Tempo"

gem. Sua bandeira? "Segurança doméstica: lutando contra o terrorismo desde 1492". Estudos organizados por áreas são uma força contrária ao etnocentrismo. Nosso trabalho, como definiu em 1920 um professor do meu departamento, "é falar sobre o mundo, para o mundo" - mas é claro que a maneira como falamos é crucial.

Igualdade. A matéria e o mundo não serão melhores até que haja maior igualdade. Devemos tomar posições. Isso significará desafiar as realidades definidas pelos poderosos, estar interessado na democracia dentro e entre os países, e falar a verdade para o poder - muito embora o poder não esteja realmente interessado em verdade, nem em democracia. A este respeito, gosto de uma história que Ivor Richard, ex-embaixador do Reino Unido nas Nações Unidas, costumava contar. Ele lembrava que havia sido perguntado por um amigo norte-americano por que as Nações Unidas eram tão não democráticas. "Não democráticas?" - Richard replicou - "por que você diz isso?". "Porque nós continuamos não sendo votados", seu amigo disse, aparentemente com seriedade.

Economia. É uma parte importante do engajamento com o real entender dos aspectos materiais da vida. Alguém um dia perguntou para um ladrão de banco: "Por que você rouba bancos?". Ele respondeu: "Porque lá é o lugar onde está o dinheiro". Nós em RI precisamos gastar mais tempo procurando onde está o dinheiro, e especialmente onde não está, se quisermos conhecer o mundo. Isso envolve entender a realidade daquilo que chamamos morte pela economia, pelo menos tanto quanto sabemos sobre a morte pela política - a violência feita sobre e por meio da pobreza tanto quanto a violência por meio da política que tem sido nossa esmagadora preocupação. Um entendimento como este foi brilhantemente elaborado por Mark Twain em seu comentário sobre a Revolução Francesa um século depois. Suas palavras soaram depois do 11 de setembro. Twain disse que havia dois terrores na vida: um ser assassinado por uma paixão 
calorosa, o outro ser assinado "a sangue frio" - um consumado rapidamente, o outro durando mil anos.

Emancipação. Que idéia deveria informar nossa teorização? Para os realistas, o poder; para os teóricos da "Escola Inglesa", a ordem; e para os teóricos críticos como eu, a emancipação. Muitos desafiam esta visão, alegando que emancipação é uma idéia vaga, utópica e eurocêntrica. Eles estão errados, na medida em que emancipação é um processo e não um ponto final, e que sua referência é a humanidade comum. O cerne da idéia não é difícil de entender - embora sua política contextual seja sempre boa para ser contestada. Um carpinteiro radical do século XX, William Lovett, expressou a essência da emancipação com grande clareza no título de um livro: The pursuit of bread, knowledge, and freedom ("A busca do pão, do conhecimento e da liberdade"). Em outras palavras, emancipação diz respeito à liberdade da opressão material, liberdade da ignorância e das mentiras, e liberdade da tirania política e da exploração econômica.

A idéia da emancipação não é difícil de entender, nem a consciência que está por trás dela. Thomas Hobbes, usualmente identificado como o frio filósofo do medo e da necessidade no nosso campo, argumentou: "A segurança das pessoas é a lei suprema”. Mas depois ele adicionou, "por segurança se deve entender não a mera sobrevivência em qualquer condição, mas uma vida feliz na medida em que isso seja possível”. As RI dizem respeito à sobrevivência, mas deveriam também tratar da emancipação - criando as condições nas quais nós todos podemos (e não somente os poderosos) viver nossas vidas pública e pessoal com espaço para o amor, o riso, a música, a dignidade e uma boa refeição.

Finalmente, Todo Mundo. Essa é uma expressão bastante elaborada para um rótulo que descreva o "nós global": humanidade comum. Se nós nas universidades não falamos e pesquisamos um "nós global" em todas as nossas complexidades de identidade e assim por diante, 


\section{“Acordem! Nossos Relógios Estão Lentos em}

Relação ao Nosso Tempo"

quem o fará? Afinal de contas, a palavra "universidade" vem de universitas, que significa "universal". Isso, eu acredito, deveria ser o ponto de partida para nos engajarmos em questionamentos críticos com a política e a economia dos negócios como sempre. O filósofo estóico Diógenes, no tempo da Grécia antiga, queria que fôssemos "cidadãos do mundo" - uma condição que ele descreveu como "um tipo de exílio". Penso que deveríamos abraçar este objetivo genérico, porém rejeitar a implicação de ser "um tipo de exílio". Em vez disso, penso que deveríamos aprender a entender o ser um cidadão do mundo como um tipo de escape da maneira como as pessoas ao longo da história têm sido exiladas umas das outras por fronteiras criadas pelo poder - exiladas umas das outras pelos jogos de poder do nacionalismo, gênero, classe, raça e tudo mais. Se nós nas universidades não falamos racionalmente em nome do universal, quem falará? E se nossa matéria não o faz, quem o fará? Nosso grande tema tem a oportunidade de ser a arcada da estrutura intelectual para explicar o mundo para o mundo, e oferecer saídas para os perigos dos negócios de sempre. Infelizmente, neste momento não se está agarrando esta oportunidade. Nossos relógios estão lentos.

Para concluir, quero repetir o desafio que fiz no começo. Convido aqueles que estão hoje nos seus 20 anos a imaginar que serão convidados a falar em 2047, quando o Instituto celebrar sessenta anos de estudos de pós-graduação. Que mundo vocês gostariam de descrever? A fim de ajudar a trazer este mundo para a existência, o que precisa, dessa forma, ser feito em sua pesquisa e ensino (e vida) - começando amanhã - para ajudar a conseguir que o desejável e o factível cheguem o mais próximo possível? O futuro começa agora.

Então, por favor, tenham uma noite de insônia pensando sobre essas coisas e, por favor, convidem-me para voltar para a comemoração do seu sexagésimo aniversário em 2047 para ouvir o que vocês têm a dizer sobre o cenário do mundo em meados do século. Posso lhes dizer desde já que eu "pularia" sobre a chance de aceitar o convite (embora 
"pular" não seja a imagem mais apropriada, porque significaria que eu teria alcançado a idade de mais de cem anos e estaria com boa saúde). Nesse meio tempo, deixem-me oferecer meus melhores votos para o futuro a todos vocês, e para o Instituto de Relações Internacionais, companheiros de estudo desse nosso fascinante e tão importante tema.

\section{Nota}

1. Este primeiro parágrafo o autor escreveu e falou em português, conforme aqui reproduzido. [N.T.] 